\title{
Review of Hardware for PTCA
}

\author{
STEVEN W. WERNS, M.D. and ERIC J. TOPOL, M.D. \\ From the Department of Internal Medicine, Division of Cardiology, University of Michigan Medical School, Ann Arbor, Michigan
}

There is a growing inventory of dilatation hardware at the disposal of the interventional cardiologist. The purpose of this review is to compare the distinguishing features of current and anticipated equipment which should be considered in the selection of hardware for performing coronary angioplasty (PTCA). New guiding catheters designed to improve "back-up" support for difficult anatomic variants include the hockey stick, the El Gamal, the Arani, the FR 3.5 ALT, and the AL 0.75 and ALR 1.2 Amplatz models. New "micro" dilatation catheters include the Mini-Profile and Skinny catheters, which combine independent wire movement and low profile shafts $(3.5 \mathrm{~F})$, and the Probe, which is currently the catheter with the lowest profile shaft $(1.7 \mathrm{~F})$ and balloon $\left(0.020^{\prime \prime}\right.$ for a 2.0-mm diameter balloon). The low profile of the Probe allows it to be used alongside a conventional $4.3 \mathrm{~F}$ dilatation catheter within the new 9 F Giant Lumen guiding catheter, which has an internal

\section{Introduction}

Although the performance of multilesion and multivessel coronary angioplasty (PTCA) has increased in frequency, the PTCA success rate has improved, in part due to advances in technology that have widened the array of dilatation hardware at the disposal of the interventional cardiologist. ${ }^{1}$ The purpose of this review is to survey the equipment that is currently in use or will soon be available, and to describe the distinguishing features

Address for reprints: Steven W. Werns, M.D., Cardiology Division, University Hospital, B1-F245, Box 0022, 1500 East Medical Center Drive, Ann Arbor, Michigan 48109.

Submitted for publication June 30, 1988; accepted August 11, 1988. diameter of 0.088 ". The forthcoming "monorail" catheters will provide the operator with a low profile, "over-the-wire" system that can be exchanged for a different balloon size or a perfusion catheter without using an extension or exchange wire. Two innovations in guidewire technology are the Dilating Guide Wire (DGW) and the Buchbinder Omniflex catheter. The DGW features a $1.5-\mathrm{mm}$ diameter balloon with a deflated profile of $0.018^{\prime \prime}$ that can be accommodated within the Trac and Trac Plus series of dilatation catheters. The Buchbinder Omniflex catheter is designed so that the distal tip of the wire can be rotated and flexed via controls on the proximal hub of the catheter, permitting shaping of the tip without removal of the catheter. Selection of appropriate equipment from the vast array of PTCA hardware will allow the operator to minimize the cost and maximize both the safety and success of dilating a coronary stenosis. (J Interven Cardiol 1988:1:3)

which should be considered in selecting appropriate guiding catheters, dilatation catheters, and guidewires.

\section{Guiding Catheters}

The desirable characteristics of a guiding catheter are back-up support, torque control, ease of contrast delivery, reliable pressure monitoring, smooth passage of the dilatation catheter, and the potential for safe deep seating. Although the $9 \mathrm{~F}$ catheters may provide the best contrast delivery, pressure monitoring, and support, the advantages are offset by the potential for coronary dissection and groin complications. The newer large lumen "high-flow" $8 \mathrm{~F}$ catheters with internal diameters up to 0.076 inches provide adequate opacification, pressure capabilities, and stiffness for most cases, 
and have largely obviated the need to resort to $9 \mathrm{~F}$ catheters. The new $9 \mathrm{~F}$ "Giant Lumen" guiding catheter (Interventional Medical) has an internal diameter of $0.088^{\prime \prime}$ that can accommodate two dilatation systems for performing kissing balloon or multivessel procedures. For example, both a Probe (USCI, Billerica, MA, USA) and an over-the-wire system can be introduced simultaneously with adequate independent mobility of each system.

Although guiding catheters for PTCA are currently produced by 5 manufacturers, the composition of the catheters is similar. The inner teflon layer provides a low coefficient of friction to permit passage of the dilatation catheter. The middle layer, which is a woven wire matrix in the majority of cases, provides torque control and support. The outer layer, which is composed of either polyurethane (Cordis, Interventional Medical, Miami, Fl, USA, Schneider Shiley, and USCI) or polyethylene (ASC), provides stiffness and memory.

Recent innovations in the construction of guiding catheters are worth noting. Compared to diagnostic coronary catheters, the tips of the first generation guiding catheters were shorter, nontapered, and had thinner walls, posing a greater risk of intimal dissection, especially during deep seating of the guiding catheter. "Soft-tipped" angiographic catheters, which were found to be less traumatic to vascular endothelium in experimental studies, ${ }^{2}$ are now marketed by several catheter companies.

Guiding catheters with tips designed for special purposes have been introduced. The new shorttipped guiding catheters (ACS, Schneider Shiley) may reduce the risk of disrupting plaques in the proximal left main or right coronary arteries. Both right and left Judkins catheters with side holes are available to lessen hypoperfusion due to catheter wedging during deep seating, which may be required for increased stability and axial support to cross a tight stenosis. Left Judkins catheters are produced with three different tip alignments: within the plane of the catheter, $30^{\circ}$ anteriorly for selective engagement of the left anterior descending artery (LAD), and $30^{\circ}$ posteriorly for engagement of the left circumflex artery (LCX). Selective engagement with a standard catheter, however, can usually be accomplished by either advancement with counterclockwise rotation (LAD) or withdrawal with clockwise rotation (LCX). Several guiding catheters possess radiopaque distal tip markers to facilitate positioning of the catheter (Interventional Medical, USCI).

Guiding catheters with medium and enhanced stiffness of the distal shaft have been developed. Medium stiffness for routine procedures is characteristic of catheters whose middle braided layer ends proximal to the "knuckle" or secondary curve. Extension of the wire braid beyond the "knuckle" to within a few centimeters of the tip segment confers maximum stiffness and back-up support.

The selection of a guiding catheter that is suitable for the anatomy of the coronary artery maximizes back-up support and facilitates crossing a stenosis with a balloon catheter. A variety of new guiding catheter shapes have been developed to deal with difficult anatomic variants that cannot be adequately engaged with the standard Judkins, Amplatz, and bypass guiding catheters (Fig. 1; Table I). The Amplatz 0.75 (Interventional Medical) is a small diameter Amplatz for right coronary arteries in small patients or patients with narrow aortic roots. The ALR1.2 (Interventional Medical) is a modified Amplatz that is sized between an AL1 and an AR2, and may be useful for a right coronary artery (RCA) or bypass graft with a superior take-off or in a patient with a dilated aortic root. The FR 3.5 ALT (Acute Longer Tip; Interventional Medical), which is a modification of a $3.5 \mathrm{~cm}$ right Judkins, may provide improved backup for cases involving a "shepherd's crook" RCA. The hockey stick catheter (Interventional Medical) is designed to work like an Amplatz catheter without the primary curve, and is less likely to dive deeply into the RCA. It is useful for working with RCA's that have a superior take-off and/or an ostial stenosis. The El Gamal (Interventional Medical, Schneider Shiley, USCI), and Arani Double Loop (Interventional Medical and USCI) catheters are useful for arteries with unusual take-offs and for bypass grafts. The El Gamal catheter is distinguished by an $80^{\circ}$ curve 4 centimeters proximal to the tip. The Arani Double Loop catheters feature a distal, primary curve of either $75^{\circ}$ or $90^{\circ}$ that is separated by a 10 centimeter arm from a proximal, secondary curve of $100^{\circ}$. The catheters are available with either $15-\mathrm{mm}$ or 26- $\mathrm{mm}$ distal tip lengths. A single side hole is located just after the primary curve. 


\section{PTCA HARDWARE}

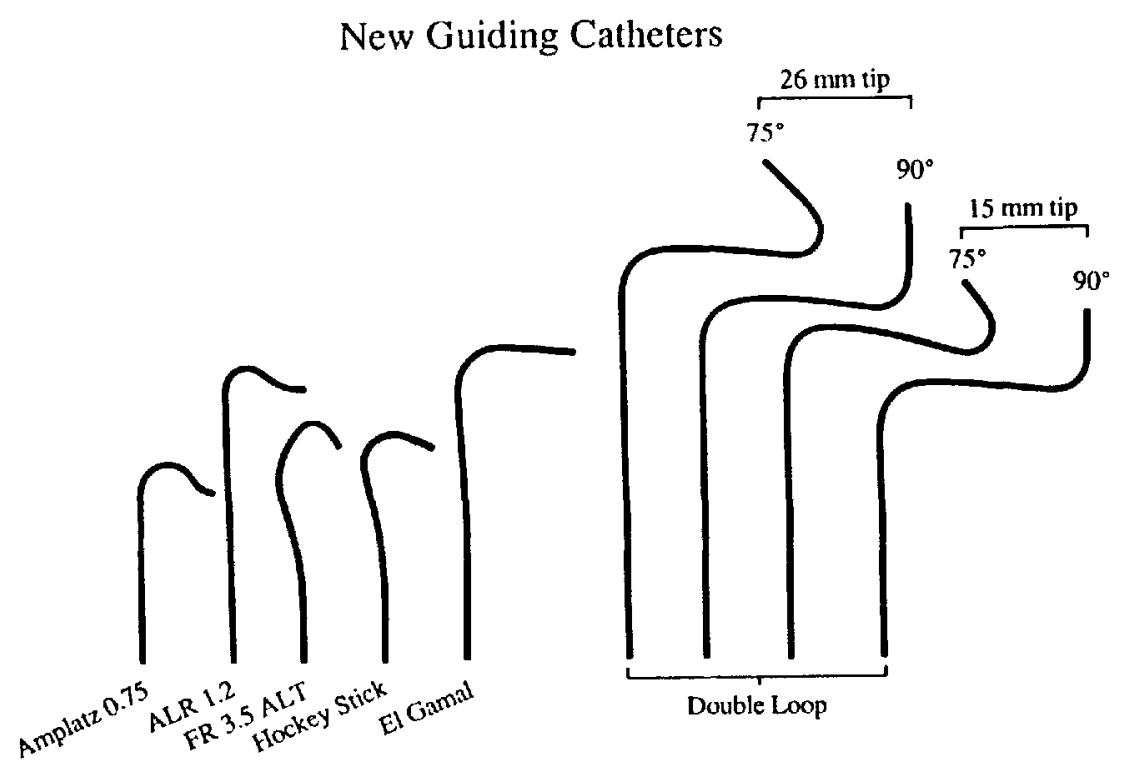

Figure 1. New PTCA guiding catheters.

The brachial approach to coronary angioplasty is an alternative to the femoral approach, and permits safe, selective engagement of the LAD or LCX in the hands of an experienced operator. The improved backup support offered by the brachial approach may be particularly helpful for extremely severe or distal stenoses, and difficult anatomic variants such as a short left main or a shepherd's crook RCA.

\section{Dilatation Catheters}

There are two basic dilatation catheter designs: a concentric lumen system and an eccentric lumen system. The concentric lumen system (ACS, SciMed) is characterized by a central lumen for the guide wire and a concentrically arranged outer lumen for balloon inflation and deflation. The eccentric lumen system (Edwards, USCI) features separate, eccentric lumens for the guide wire and for balloon inflation/deflation. The advantage of the eccentric lumen design is the capability of using the distal guidewire lumen to inject contrast and measure the transstenotic pressure gradient. The concentric lumen design sacrifices gradient measurement and contrast delivery in exchange for a lower profile and faster balloon inflation and deflation.
An additional difference between dilatation catheters is the construction of the catheter shaft and balloon. Catheter shafts are constructed of either polyvinylchloride (USCI except Simplus and Mini-Profile), or polyethylene (ACS, Edwards, Mansfield, SciMed, USCI Simplus). Maximum "pushability" is provided by catheters with a polyvinylchloride shaft, while maximum "trackability" is obtained with a polyethylene shaft. Several catheters have flexible necks proximal to the balloon to enhance tracking, e.g., LoProfile II, Profile Plus, TracPlus, MicroTracPlus. The XT model of the Hartzler Micro catheter is characterized by a reinforced proximal shaft for increased "pushability."

Balloons are composed of either polyethylene (ACS, Edwards, Mansfield), polyethylene terephthalate or PET (Schneider Shiley, USCI except LoProfile models), polyvinylchloride (USCI LoProfile models), or polyolefin (SciMed). Balloons constructed of polyvinylchloride, which has a greater compliance than polyethylene, can be stretched to $0.2-0.5 \mathrm{~mm}$ greater than the nominal size, allowing greater dilatation of stenoses by inflation to a higher pressure. Polyethylene has a lower coefficient of friction than polyvinylchloride, making the balloon better suited for traversing tortuous vessels and critical stenoses. The Edwards Hydracross catheter (investigational at the 
WERNS ET AL.

Table I. Guiding Catheters

\begin{tabular}{|c|c|c|c|c|c|}
\hline & ACS & CORDIS & IM & SHILEY & USCI \\
\hline \multicolumn{6}{|l|}{ ID (in) } \\
\hline $7 F$ & - & - & - & 0.063 & - \\
\hline $8 \mathrm{~F}$ & 0.072 & 0.074 & 0.076 & 0.076 & 0.072 \\
\hline $9 \mathrm{~F}$ & 0.076 & - & 0.088 & 0.080 & - \\
\hline Outer layer & PE & PU & PU & PU & PU \\
\hline Tip softness & $+1-$ & + & + & + & + \\
\hline Distal Markers & $-*$ & - & + & - & + \\
\hline Judkins & $\begin{array}{l}R, 3-6 \\
L, 3.5-6\end{array}$ & $\begin{array}{l}\mathbf{R}, 3.5-6 \\
\text { L, 3.5-6 }\end{array}$ & $\begin{array}{l}\mathrm{R}, 3.5-6 \\
\mathrm{~L}, 3.5-6 \\
\mathrm{R} 3.5 \mathrm{ALT}\end{array}$ & $\begin{array}{l}R, 3-6 \\
L, 3-6\end{array}$ & $\begin{array}{l}\mathbf{R}, 3.5-6 \\
\mathrm{~L}, 3.5-5\end{array}$ \\
\hline Amplatz & $\begin{array}{l}\mathrm{R}, 1-3 \\
\mathrm{~L}, 1-4\end{array}$ & $\begin{array}{l}\text { R, I } \\
\text { L, } 1 \text { \& } 2\end{array}$ & $\begin{array}{l}\text { R, } 1 \& 2, \text { FRS } \\
\text { L, } 0.75-4 \\
\text { ALR } 1.2\end{array}$ & $\begin{array}{l}\text { R, } 1 \& 3 \\
\mathrm{~L}, 1 \& 3\end{array}$ & $\begin{array}{l}\mathrm{R}, 1 \& 2 \\
\mathrm{~L}, 1 \& 2\end{array}$ \\
\hline Bypass & $8 \mathrm{~F}$ IntM & $8 F$ Bypass & $\begin{array}{l}\text { R \& L } \\
\text { IntM, El Gamal }\end{array}$ & $\begin{array}{l}\text { 7-9F, R \& L } \\
\text { IntM, El Gamal }\end{array}$ & $\begin{array}{l}\text { 8F, R \& L } \\
\text { IntM, El Gamal }\end{array}$ \\
\hline Short tip & 9FR & - & - & $7-9 F, L$ & - \\
\hline Side hole & $8 \& 9 F, R$ & No & Yes & 7-9F, R \& L & $8 F, \mathbf{R}$ \\
\hline Other & - & 8F Multipurpose & $\begin{array}{l}\text { Multipurpose } \\
\text { Arani } \\
\text { Hockey Stick }\end{array}$ & $\begin{array}{l}\text { 7-9F Multipurpose } \\
8 \mathrm{~F} \text { Brachial }\end{array}$ & $\begin{array}{l}\text { 8F Multipurpose } \\
\text { 8F Arani }\end{array}$ \\
\hline \multirow[t]{3}{*}{ Options } & $\begin{array}{l}\text { Canted left }(9 \mathrm{~F}) \\
\text { Enhanced Torque } \\
8 \text { F } 7.5 \text { tip }\end{array}$ & $\begin{array}{l}\text { Standard \& } \\
\text { Modified tips } \\
-\end{array}$ & Canted left $(8 \mathrm{~F})$ & Canted left $(7-9 F)$ & $\begin{array}{l}\text { Standard } 3 \mathrm{~cm} \text { tip } \\
8 \mathrm{~cm} \text { flexible tip }\end{array}$ \\
\hline & $\begin{array}{l}\text { 9/8F Taper Tip } \\
\text { (9F shaft with } 8 \mathrm{~F} \text { tip) }\end{array}$ & $\begin{array}{l}\text { Medium \& Firm } \\
\text { Shaft stiffness }\end{array}$ & - & - & - \\
\hline & "9/8F Taper Tip only & & & & \\
\hline
\end{tabular}

$\mathrm{ID}=$ inner diameter; $\mathrm{PE}=$ polyethylene; $\mathrm{PU}=$ polyurethane; IntM = internal mammary.

time this paper was written) is distinguished by a polyethylene balloon treated with hydrophilic acrylamide polymers that are designed to reduce the coefficient of friction between the balloon and the stenosis.

Several factors must be considered in the selection of a dilatation catheter for a particular situation. One of the first considerations is the balloon size, which should be large enough to adequately dilate the target vessel lumen without inducing a complex dissection. A recently reported randomized trial showed an increased incidence of dissection, myocardial infarction, and emergency bypass surgery after angioplasty in patients dilated with slightly oversized balloons (ratio of balloon to artery diameter $=1.13$ ) compared to slightly undersized balloons (balloon to artery diameter $=0.93$ ). ${ }^{3}$ Occasionally, tight stenoses in large arteries will require sequential dilation with small followed by larger balloons. Alternatively, a tight stenosis that cannot be crossed with a large balloon may be dilated by the so-called "dilating guidewire" that is described below.

A second consideration is whether to use a system with a fixed wire, e.g., Hartzler LPS, semi-independent wire, e.g., Hartzler Micro, or independent wire. The latter may be especially desirable to permit re-crossing a stenosis with a balloon or "auto-perfusion" catheter when dilating a lesion at high risk for dissection or abrupt closure, or in high-risk patients. The use of extension or "long wire" exchange techniques permits constant "purchase" on the artery for different balloon sizes or systems. Thus, the independent over-the-wire system provides a maximal safety profile.

Reliable distal pressure measurements are often difficult to obtain, especially when dilating a distal stenosis or one in a tortuous vessel. Nevertheless, recent studies suggest that the post-dilatation transstenotic pressure gradient may identify patients at increased risk of acute complications ${ }^{4}$ and restenosis. ${ }^{5}$ Thus, catheters that provide the capa- 
bility of measuring the distal coronary pressure may be advantageous under some circumstances (Table II). They include the ACS Delta catheter, the Edwards Hybrid PTCA catheter, the Mansfield Heart Trak III catheter, the Schneider Shiley Microsoftrac catheter (not currently available in the U.S.), the SciMed Trac and Trac Plus catheters, and the USCI catheters except for the Probe, the Simplus, and the Mini-Profile.

One disadvantage of the catheters which allow distal pressure measurement is limited proximal contrast delivery because the shaft sizes are $4.3 \mathrm{~F}$ or greater. Enhanced proximal contrast delivery is provided by a number of catheters that possess a lower shaft profile. The shaft of the Hartzler Micro ranges from $3.4 \mathrm{~F}$ to $4.1 \mathrm{~F}$, while the shaft of the Hartzler LPS ranges from $2.9 \mathrm{~F}$ to $4.3 \mathrm{~F}$. The USCI Mini-Profile catheter has a $3.5 \mathrm{~F}$ shaft. The SciMed Skinny has a shaft that is $3.5 \mathrm{~F}$ with a distal taper to 3.0 F. The Schneider Shiley Monorail-Bonzel catheter, which is not available in the U.S., has a $3.0 \mathrm{~F}$ shaft. Both the Buchbinder Omniflex catheter and the ACS Mini catheter have a $2.9 \mathrm{~F}$ shaft. The Probe has the smallest shaft, $1.7 \mathrm{~F}$. The USCI Mini-Profile, the SciMed Skinny, and the Schneider Shiley Monorail catheters are overthe-wire systems, while the Hartzler Micro and LPS, the Buchbinder Omniflex, and the ACS Mini cannot be exchanged over a guidewire.

Successful crossing of a stenosis may depend on not only guiding catheter support and the shaft stiffness of the dilatation catheter, but also the balloon profile and taper. Several new "micro" systems with "low profile" balloons have become available recently. The deflated balloon profiles are tabulated in Table III, and Figures 2 and 3 illustrate the relative profiles of $2.0-\mathrm{mm}$ diameter and $3.0-\mathrm{mm}$ diameter balloons. According to the manufacturers' specifications, the "over-the-wire"

Table II. Dilatation Catheters that Permit Distal Pressure Monitoring and Contrast Injection

ACS Delta

Edwards Hybrid

Mansfield Heart Trak III

Schneider Shiley Microsoftrac

SciMed Trac and Trac Plus

USCI LPS, LoProfile II, Profile Plus systems with the lowest $2.0-\mathrm{mm}$ balloon profiles currently available in the United States (at the time this paper was written) are the SciMed Micro Trac $\left(0.036^{\prime \prime}\right)$, the Schneider Shiley Microsoftrac $\left(0.035^{\prime \prime}\right)$, the USCI Simplus PE/t $\left(0.034^{\prime \prime}\right)$, the USCI Profile Plus $\left(0.033^{\prime \prime}\right)$, the USCI Mini-Profile $\left(0.031^{\prime \prime}\right)$, and the SciMed Skinny (0.031"). The Profile Plus and the Microsoftrac have the added benefit of distal pressure monitoring. Although the SciMed Skinny and the USCI Mini-Profile lack the capability of monitoring distal pressure, their 3.5 F shafts enhance dye injection and opacification of the stenosis. The profiles of the Skinny and Mini-Profile are especially impressive because the shaft sizes are the same for the 2.0, 2.5, and 3.0$\mathrm{mm}$ balloon catheters, while the shafts of the Hartzler models increase as the balloon size increases. The shaft of the 2.0-mm Hartzler Micro is $3.4 \mathrm{~F}$, but the $3.0-\mathrm{mm}$ Micro has a $3.9 \mathrm{~F}$ shaft. Similarly, the $2.0 \mathrm{~mm}$ Hartzler LPS has a $2.9 \mathrm{~F}$ shaft, but the shaft of the $3.0-\mathrm{mm}$ LPS is $3.5 \mathrm{~F}$. There is also a steeper increase in balloon profiles for the Hartzler catheters. The profiles of the 2.0$\mathrm{mm}$ balloons are $0.031^{\prime \prime}$ for the Mini-Profile and Skinny, compared to $0.035^{\prime \prime}$ for the Hartzler LPS. The profiles of the $3.0-\mathrm{mm}$ balloons are $0.035^{\prime \prime}$ for the Mini-Profile, 0.037" for the Skinny, and 0.046" for the Hartzler LPS (Table III; Fig. 2 and 3). Thus, for the dilatation of large arteries, the Mini-Profile and the Skinny catheters combine the safety of an over-the-wire system with lower balloon and shaft profiles than those of the fixed wire systems.

The lowest profile fixed wire catheters are the ACS Mini, Hartzler Micro, and Hartzler LPS catheters and the USCI Probe. The ACS Mini is produced in one balloon size, $1.3 \mathrm{~mm}$, which has a deflated balloon profile of $0.025^{\prime \prime}$. Although the Hartzler catheters have small shafts which facilitate proximal contrast delivery, the profiles of the balloons are not particularly low. The $2.0-\mathrm{mm}$ diameter balloon Hartzler Micro and Micro XT have a $3.4 \mathrm{~F}$ distal shaft and a deflated balloon profile of $0.038^{\prime \prime}$. The proximal shaft of the Micro $\mathrm{XT}$ is reinforced for enhanced stiffness and has a 3.8 $\mathrm{F}$ diameter. The $2.0-\mathrm{mm}$ diameter Hartzler LPS has a $2.9 \mathrm{~F}$ diameter shaft and the balloon has a collapsed profile of $0.035^{\prime \prime}$. The Micro and Micro XT models have a semi-independent wire ( 2 or $3-\mathrm{cm}$ tips) and the LPS has a fixed wire (1, 2, or $3-\mathrm{cm}$ tip). Thus, the balloon catheter cannot be 
WERNS ET AL.

Table III. Dilation Catheters

\begin{tabular}{|c|c|c|c|c|c|c|c|c|c|}
\hline \multirow[b]{3}{*}{ Type } & \multirow[b]{3}{*}{$\begin{array}{l}\text { Shaft Diameter } \\
\text { (F) }\end{array}$} & \multirow{3}{*}{$\begin{array}{c}\text { Balloon } \\
\text { Length } \\
(\mathrm{mm})\end{array}$} & \multicolumn{6}{|c|}{ Inflated Balloon Diameter (mm) } & \multirow[b]{3}{*}{$\begin{array}{l}\text { Max } \\
\text { Wire }\end{array}$} \\
\hline & & & 1.5 & 2.0 & 2.5 & 3.0 & 3.5 & 4.0 & \\
\hline & & & \multicolumn{6}{|c|}{ Deflated Balloon Profile (in) } & \\
\hline \multicolumn{10}{|l|}{$A C S-P E$ Balloon \& shaft } \\
\hline Simpson-Robert & $4.3-4.7$ & 20 & - & .045 & .050 & .055 & .062 & .063 & .018 \\
\hline Simpson Ultra Low Profile & $4.3-4.7$ & 20 & - & .040 & .046 & .049 & - & - & .014 \\
\hline Delta & $4.3-4.7$ & 20 & - & .044 & .050 & .054 & .062 & .062 & .018 \\
\hline Hartzler LPS $(1,2,3 \mathrm{~cm}$ tips $)$ & $2.9-4.3$ & 20 & .031 & .035 & .044 & .046 & .052 & .060 & - \\
\hline Hartzler Micro $(2,3 \mathrm{~cm}$ tips) & $3.4-4.1$ & 20 & .037 & .038 & .044 & .048 & .053 & - & 一 \\
\hline Hartzler Micro XT $(2,3 \mathrm{~cm}$ tips $)$ & $3.8-4.2$ & 20 & .037 & .038 & .044 & .048 & .053 & - & - \\
\hline Angled Balloon & 4.3 & 25 & - & .047 & .057 & .061 & - & - & .018 \\
\hline Mini & 2.9 & 20 & $.025+$ & - & - & - & - & - & - \\
\hline \multicolumn{10}{|l|}{ Baxter Edwards PE balloon \& shaft } \\
\hline Hybrid & 4.3 & 20 & - & .043 & .046 & .052 & .054 & - & .018 \\
\hline Hydracross (Investigational)* & 4.3 & $?$ & $?$ & $?$ & $?$ & $?$ & $?$ & - & $?$ \\
\hline \multicolumn{10}{|l|}{ Mansfield-PE balloon \& shaft } \\
\hline Heart Trak III & $?$ & 20,25 & - & .040 & .046 & .051 & .053 & .059 & $?$ \\
\hline Max Trak (Investigational)* & $?$ & 20,25 & $?$ & $?$ & $?$ & $?$ & $?$ & $?$ & $?$ \\
\hline \multicolumn{10}{|l|}{ Schneider Shiley } \\
\hline $\begin{array}{l}\text { Microsoftrac* } \\
\text { (Pet balloon, polyester shaft) }\end{array}$ & 4.3 & 20 & .033 & .035 & .044 & .046 & .048 & .050 & .014 \\
\hline Monorail-Bonzel* & 3.0 & 20 & .032 & .034 & .036 & .040 & .042 & .044 & .014 \\
\hline Monorail-Bonzel Snake ${ }^{*}$ & 3.0 & $10,20,25+\dagger$ & $\div$ & - & - & - & - & - & .012 \\
\hline Monorail-Bonzel Pass-key* & 3.0 & $10,20,25+t$ & $\dot{r}$ & - & - & - & - & - & .010 \\
\hline \multicolumn{10}{|l|}{ SciMed-Polyolefin balloon, PE shaft } \\
\hline Skinny & 3.5 tapered to 3.0 & 20 & - & .031 & .033 & .037 & - & - & .014 \\
\hline Trac & 4.3 & 20 & - & .040 & .046 & .049 & .053 & .059 & .018 \\
\hline Trac Plus & 4.3 & 20 & - & .040 & .046 & .049 & .053 & .059 & .018 \\
\hline Micro Trac & 4.3 & 20 & - & .036 & .038 & .043 & - & - & .014 \\
\hline Micro Trac Plus & 4.3 & 20 & - & .036 & .038 & .043 & - & - & .014 \\
\hline \multicolumn{10}{|l|}{ USCI-PVC balloon and shaft } \\
\hline LoProfile Steerable & 4.3 & 25 & - & .039 & .047 & .050 & .051 & .053 & $.018^{* *}$ \\
\hline LoProfile II & 4.3 & 20 & - & .036 & .047 & .050 & .051 & .053 & $.018^{* *}$ \\
\hline LoProfile II Short & 4.3 & 12 & - & .036 & .047 & .050 & - & - & $.018^{* *}$ \\
\hline \multicolumn{10}{|l|}{ USCI-Pet balloon } \\
\hline Profile Plus-PVC shaft & 4.3 & 20 & - & .033 & .038 & .039 & .040 & .041 & $.018^{* *}$ \\
\hline Simplus PE/t-PE shaft & 4.3 & 20 & - & .034 & .034 & .036 & .037 & .042 & $.018^{* * *}$ \\
\hline Probe-wire shaft, PE neck & $.022^{\prime \prime}$ & 15,20 & - & .020 & .025 & .030 & - & - & - \\
\hline Mini-Profile-PE shaft & 3.5 & 20 & - & .031 & .033 & .035 & .037 & - & .018 \\
\hline \multicolumn{10}{|l|}{ Versaflex-PE balloon and shaft } \\
\hline Buchbinder Omniflex & 2.9 & 20 & - & .034 & .038 & .042 & .046 & - & - \\
\hline
\end{tabular}

$+1.3 \mathrm{~mm}$ inflated balloon diameter

* Not available in U.S.

† Monorail-Bonzel Snake available with 3.0-4.2 $\mathrm{mm}$ balloons with distal pressure capability.

t† Monorail-Bonzel Snake and Passkey available in short $(10 \mathrm{~mm})$ and standard lengths.

** Pressure monitoring may be compromised by .016 in $2.0 \mathrm{~mm}$ and by $.018 \mathrm{in} 3.0-4.0 \mathrm{~mm}$ balloons. .018 not recommended for 2.0 mm balloons.

$\mathrm{PE}=$ polyethylene, $\mathrm{PVC}=$ polyvinylchloride, $\mathrm{Pet}=$ polyethylene terephthalate. 


\section{PTCA HARDWARE}

\section{Deflated Profiles \\ of $2.0 \mathrm{~mm}$ Balloons}

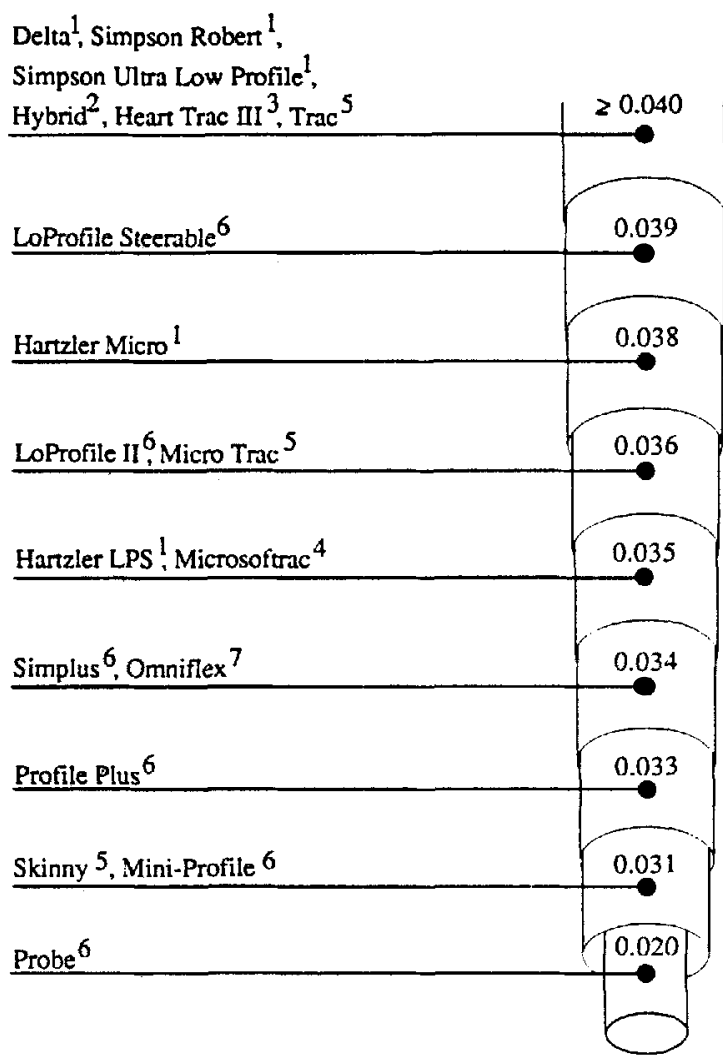

Figure 2. Deflated profiles of $2.0 \mathrm{~mm}$ balloons drawn to scale. 1 = ACS; 2 = Edwards; 3 = Mansfield; $4=$ Schneider Shiley; 5

$=$ SciMed; $6=$ USCI; $7=$ Versaflex.

exchanged over a guidewire to position a "bailout" autoperfusion catheter across a stenosis that closes abruptly. In some cases, an additional wire can be inserted alongside the Hartzler catheter to assure sustained "purchase" of the vessel.

The USCI Probe combines the smallest catheter shaft $(1.7 \mathrm{~F})$ and the lowest balloon profile available $\left(0.020^{\prime \prime}\right.$ for a $2.0-\mathrm{mm}$ balloon). The proximal shaft is a Teflon-coated stainless steel hypodermic tube that has a diameter of $0.022^{\prime \prime}(1.7 \mathrm{~F})$, while the distal $25 \mathrm{~cm}$ consists of a polyethylene neck over a tapered core wire. ${ }^{6,7}$ The balloon is composed of PET and there is a distal wire tip that is 2 $\mathrm{cm}$ in length and has a diameter of either $0.014^{\prime \prime}$ ( $2.0-\mathrm{mm}$ diameter balloon) or $0.016^{\prime \prime}$ ( 2.5 or 3.0 $\mathrm{mm}$ balloons). The initial experience with the Probe indicates that it is an important addition to the inventory of dilatation catheters. ${ }^{6,7}$ Dorros et al. ${ }^{7}$ reported their results with the Probe after failing to cross stenoses with at least two standard angioplasty catheters and a $2.0-\mathrm{mm}$ diameter Hartzler LPS (ACS) catheter. The Probe crossed the lesion in 13 of 15 cases, and successful dilatation was achieved in 12 of the $13 .^{7}$ The angioplasty result can be assessed without removing the catheter because the low profile permits excellent contrast injections. Also, the Probe's low profile allows it to be used alongside a conventional $4.3 \mathrm{~F}$ dilatation catheter within a $9 \mathrm{~F}$ Giant Lumen guiding catheter (IM), greatly simplifying the dilatation of

\section{Deflated Profiles of $3.0 \mathrm{~mm}$ Balloons}

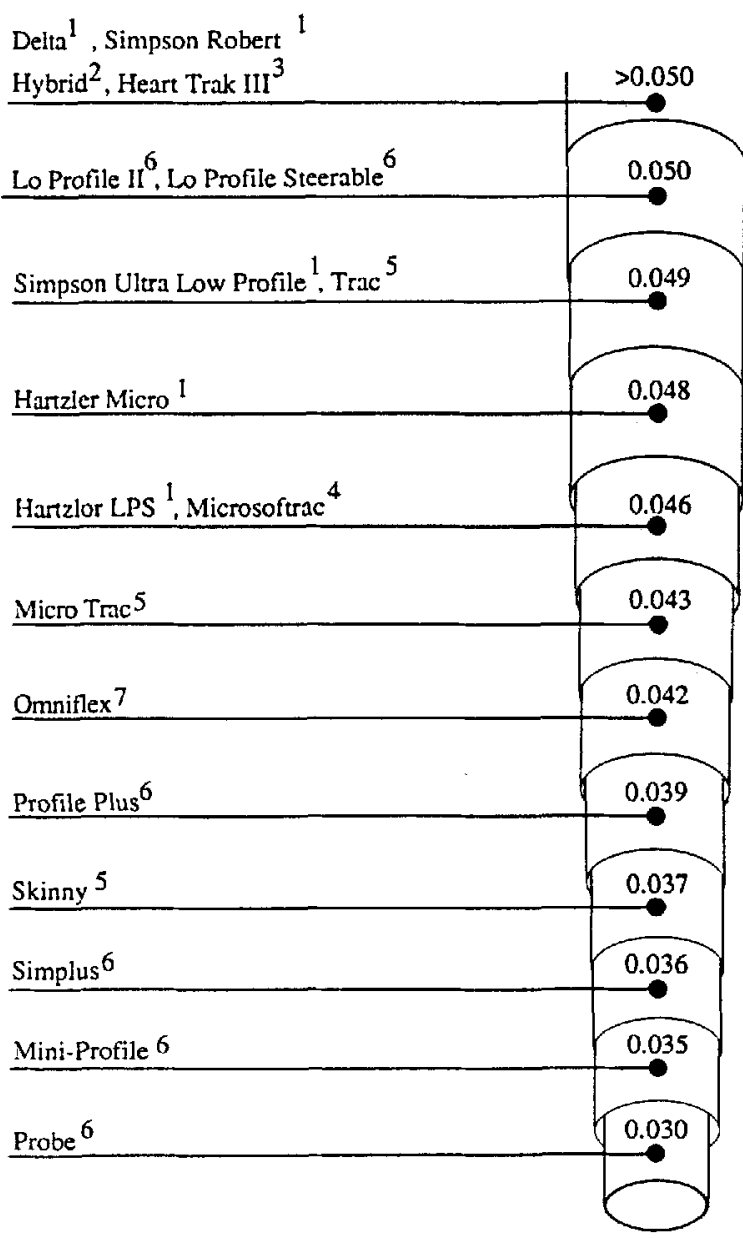

Figure 3. Deflated profiles of $3.0 \mathrm{~mm}$ balloons drawn to scale. Key as in Figure 2. 
bifurcation lesions using the "kissing wire" technique. The shortcomings of the Probe are analogous to those of the Hartzler catheters: lack of a distal port for pressure measurement or contrast injection, and the inability to exchange over a wire for another catheter. A new $4.0 \mathrm{~F}$ sheath that has been developed for use with the Probe allows exchange from a conventional over-the-wire system to the Probe. The design of the Probe's sheath, however, provides suboptimal torque control and permits considerable back-bleeding. Modification of the Probe will be necessary in order to exchange it for a long wire without having to recross the lesion.

The SciMed Dilating GuideWire is a guidewire with a $1.5-\mathrm{mm}$ diameter $20-\mathrm{mm}$ length balloon. The profile of the collapsed balloon is $0.018^{\prime \prime}$. Therefore, the wire can be accommodated within the SciMed Trac and Trac Plus catheters, and can be used to "pre-dilate" tight stenoses that cannot be crossed with conventional dilatation catheters.

Two special-purpose balloons that have become available recently are the Lo Profile II Short catheter (USCI) which is distinguished by a $12-\mathrm{mm}$ balloon length, and the Angled Balloon catheter (ACS), which features a $25-\mathrm{mm}$ balloon length with a $135^{\circ}$ angle. Both catheters are designed for over-the-wire use and may be well suited for dilatation of lesions situated at vessel bends or bifurcations, but there are no published data comparing them to standard dilatation catheters. Another new balloon, the SciMed Strong balloon, is exceptionally resistant to bursting (average burst pres- sure of 17-18 atm) and may be useful for dilating heavily calcified stenoses.

The monorail catheters are an innovation that is eagerly anticipated. The Schneider Shiley Monorail-Bonzel system, which is currently available in Europe, is a balloon with a guidewire lumen confined to the balloon itself (Fig. 4). Thus, the guidewire runs parallel to the catheter shaft within the guiding catheter, entering the balloon at the distal end of the catheter. Therefore, the balloon catheter can be retracted and exchanged for a different balloon size or a perfusion catheter without using an extension or exchange wire. The $3.0 \mathrm{~F}$ shaft should permit excellent proximal contrast injection. The maximum recommended guidewire is 0.014 ". The reported deflated balloon diameter is $0.034^{\prime \prime}$ for a $2.0-\mathrm{mm}$ balloon. Finci et al. ${ }^{8}$ reported successful dilatation of 62 of 73 stenoses $(85 \%)$ with the Monorail catheter. Three total occlusions that could not be crossed with the Monorail catheter were subsequently crossed and dilated with a standard 3.0 balloon. ${ }^{8}$ Two stenoses could not be crossed with any of the balloons that were selected. Variants of the Monorail-Bonzel system include a "Snake" model that has a flexible 9-cm terminus designed for tortuous vessels, and a "Pass-Key" model for use with a 0.010 " guidewire. The "Snake" and "Pass-Key" models are manufactured with $10 \mathrm{~mm}, 20 \mathrm{~mm}$, and $25 \mathrm{~mm}$ length balloons. There is also a $3.6 \mathrm{~F}$ "Snake" catheter that permits distal pressure measurement. The ACS "Rapid Exchange" monorail system is being evaluated in clinical trials.

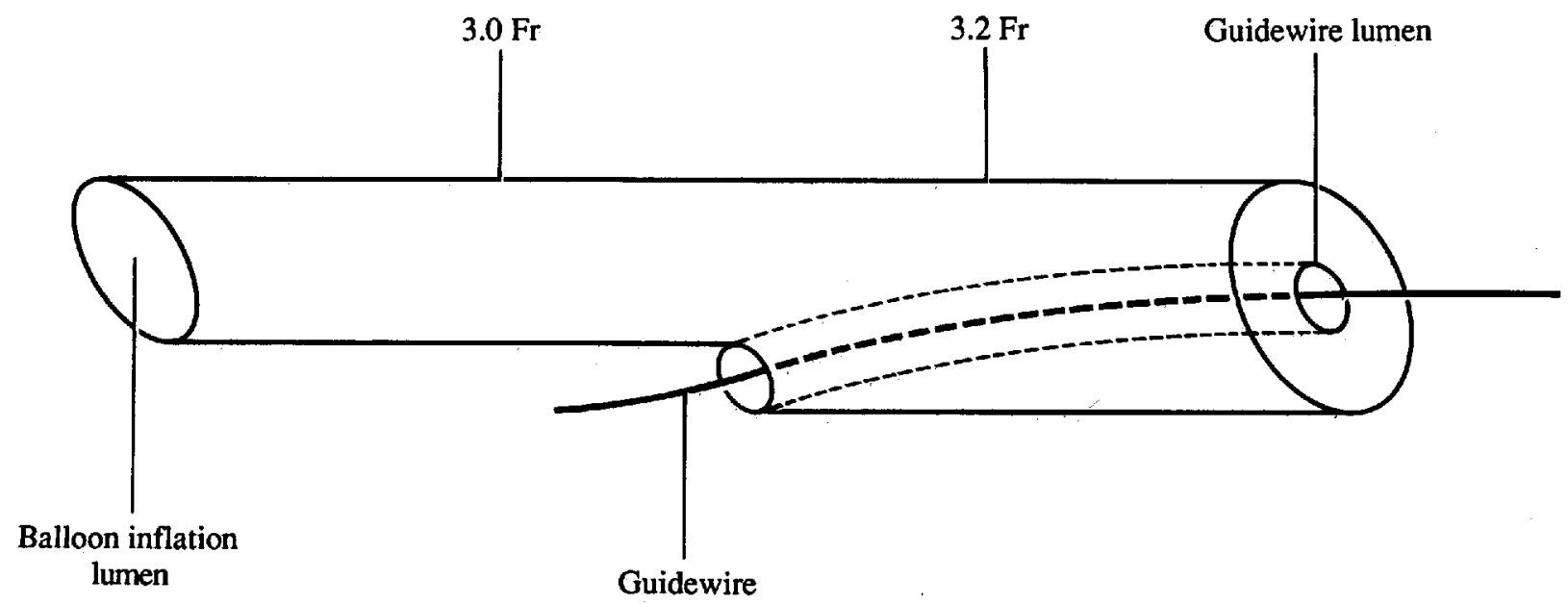

Figure 4. Schematic diagram of Schneider Shiley monorail PTCA catheter. 


\section{PTCA HARDWARE}

Another innovative dilatation catheter is the Buchbinder Omniflex catheter (Versaflex). The catheter is designed so that the distal tip of the wire can be rotated and flexed via controls on the proximal end of the catheter, potentially allowing more extensive wire tip control. The catheter shaft has a $2.9 \mathrm{~F}$ diameter and consists of a spring coil coated with polyethylene. The drawbacks of the catheter are that it is not exchangeable over a guidewire and it lacks a distal port for contrast injection or pressure monitoring. The profile of the $2.0-\mathrm{mm}$ balloon is relatively low $\left(0.034^{\prime \prime}\right)$.

\section{Guidewires}

The spectrum of PTCA guidewires ranges from "full-body" wires with maximal steerability and trackability, to "flexible" or "floppy" wires with maximal flexibility (Table IV). The "full-body" wires, the ACS Hi-Torque Standard and USCI Standard, have cores that extend to the tip, providing maximum torque control and forward support, and ease of shaping, but also the greatest risk of intimal injury. Thus, they are most suited for crossing total or subtotal occlusions. The more

Table IV. Guidewires

\begin{tabular}{|c|c|}
\hline \multicolumn{2}{|l|}{$\overline{\mathrm{ACS}}$} \\
\hline $.014, .018$ & Hi-Torque standard \\
\hline $.014, .018$ & Hi-Torque intermediate \\
\hline $.014, .018$ & Hi-Torque floppy ( 175 and $300 \mathrm{~cm}$ exchange) \\
\hline $.014, .018$ & Hi-Torque floppy with Microglide \\
\hline .014 & PDT \\
\hline .018 & Exchange Guide Wire $(300 \mathrm{~cm})$ \\
\hline .014 & DOC Guide Wire Extension $(125 \mathrm{~cm})$ \\
\hline \multicolumn{2}{|c|}{ Schneider Shiley } \\
\hline $.012, .014$ & Steerable-straight \& J \\
\hline $.012, .018$ & Super Floppy-straight \& J \\
\hline .010 & Monorail-Floppy-straight \& J \\
\hline \multicolumn{2}{|l|}{ Sci-Med } \\
\hline .018 & $\begin{array}{l}\text { Dilating Guide Wire (DGW): wire with } 1.5 \\
\text { mm balloon }\end{array}$ \\
\hline \multicolumn{2}{|l|}{ USCI } \\
\hline $.014, .016$ & Standard-J only, core wire to tip \\
\hline $.014, .016$ & $\begin{array}{l}\text { Flex-straight \& J, core wire to within } 2 \mathrm{~cm} \\
\text { of tip }\end{array}$ \\
\hline .014 & $\begin{array}{l}\text { Veri Flex-straight } \& \mathrm{~J} \text {, core wire to within } 3 \\
\mathrm{~cm} \text { of tip }\end{array}$ \\
\hline $.014, .016$ & $\begin{array}{l}\text { Hi-Per Flex-J, core wire to within } 2 \mathrm{~cm} \text { of } \\
\text { tip with taper to } 32 \mathrm{~cm} \text { ( } 25 \text { for other wires) }\end{array}$ \\
\hline .016 & Extension $(122 \mathrm{~cm})$ \\
\hline .014 & LINX ${ }^{\mathrm{TM}}$ Extension $(122 \mathrm{~cm})$ \\
\hline .014 & Exchange $(300 \mathrm{~cm})$ \\
\hline
\end{tabular}

flexible wires, which have cores that extend to within 2 or 3 centimeters of the tip (USCI Flex and VeriFlex, and ACS Hi-Torque Intermediate and Floppy), are less easily shaped, but also less likely to traumatize the coronary intima. Therefore, they are recommended for use in tortuous arteries with acute angles.

An additional difference between wires is the length of the distal segment which is radiopaque. The USCI series of wires has a radiopaque, platinum distal segment that extends 25 centimeters from the tip, while the distal radiopaque segment of the ACS wires is only 2 centimeters in length.

In the past, exchanging dilatation catheters could be accomplished by removing the standard guidewire and inserting a $300 \mathrm{~cm}$ exchange wire. The recent development of extendable guidewires has greatly simplified the process of exchanging dilatation catheters. Currently, two types of extension wires are available. The USCI extension wire is inserted into the proximal end of the guidewire and "crimped" in place. The ACS extension wire, which is designated the DOC (detachable on command) guidewire extension, is compatible with the Hi-Torque Floppy II guidewires. Recently, USCI introduced a new extension wire that does not require crimping and is detachable. The advantage of these latter extension wire systems is their ease of detachment and the absence of a crimp, which may cause resistance to wire and balloon movement.

One approach to dilating tight stenoses is to begin with a $2.0-\mathrm{mm}$ balloon, and finish the angioplasty with a larger balloon by exchanging catheters over a guidewire. For such cases, many operators prefer to simply use a Probe or other fixed wire, low profile system. The new Dilating Guide Wire, or DGW (SciMed), provides an alternative method that may obviate the need to exchange catheters. The DGW, which has a $1.5-\mathrm{mm}$ balloon, can be inserted through the lumen of the SciMed Trac or Trac Plus dilatation catheters and inflated to predilate the stenosis. The DGW has a $3-\mathrm{cm}$ flexible tip that has a diameter of $.014^{\prime \prime}$, and the shaft of the DGW is $1.7 \mathrm{~F}$.

The guidewires that are currently available in the U.S. range in diameter from $0.018^{\prime \prime}$ to $0.014^{\prime \prime}$. Guidewires with diameters of $0.012^{\prime \prime}$ or $0.010^{\prime \prime}$ are available in Europe for use with the Schneider Shiley Monorail-Bonzel dilatation system. The larger caliber wires have the potential to provide 


\section{WERNS ET AL.}

greater forward support for the dilatation catheter, but may be more likely to cause intimal damage, and interfere with monitoring the distal pressure and the injection of contrast. Therefore, it is our practice to utilize the $0.014^{\prime \prime}$ flexible wires for approaching most stenoses. The $0.016^{\prime \prime}, 0.018^{\prime \prime}$, and standard wires are reserved for total occlusions or stenoses that cannot be reached with flexible wires. The maximum compatible guidewire diameter for each type of dilatation catheter is noted in Table III.

\section{Autoperfusion Catheters}

Despite the availability of emergency surgical backup, coronary angioplasty that is complicated by abrupt closure can result in myocardial infarction or death if coronary blood flow is not restored promptly. Therefore, the placement of a "bailout" autoperfusion catheter can be life-saving. Case reports have documented the restoration of coronary blood flow and resolution of chest pain and ST-segment elevation after placement of an autoperfusion catheter after coronary artery occlusion during PTCA. ${ }^{9,10}$ The ACS autoperfusion catheter has a polyethylene $4.5 \mathrm{~F}$ shaft with 36 side holes in a spiral configuration along the distal 10 $\mathrm{cm}$. The USCI autoperfusion catheter has a PVC 4.3 F shaft with 40 side holes along the distal 12 $\mathrm{cm}$. Both catheters accommodate guidewires up to $0.018^{\prime \prime}$ in diameter.

It has been hypothesized that prolonged balloon inflations during coronary angioplasty might reduce the incidence of both abrupt closure and long-term restenosis. Myocardial ischemia during transient coronary artery occlusion, however, limits the duration of balloon inflation. Several experimental studies have explored the feasibility of providing continuous distal coronary perfusion during prolonged balloon inflation by using autoperfusion catheters which allow blood to enter through proximal side holes, pass through the central lumen, and exit through distal side holes. ${ }^{11,12}$ The USCI autoperfusion balloon catheter is a 4.3 $F$ catheter with eight sideholes proximal and three sideholes distal to the balloon, and a distal endhole (Fig. 5). The sideholes have a diameter of $0.3 \mathrm{~mm}$ and communicate with the central lumen. Inflation of the catheter's balloon in a canine coronary artery for 3 minutes did not produce ST-segment elevation, and the regional myocardial blood flow was significantly greater than during inflation of a standard balloon catheter. ${ }^{11}$ The ACS autoperfusion catheter has a $4.5 \mathrm{~F}$ shaft with 14 sideholes linearly distributed over the distal $10 \mathrm{~cm}$. Four of the sideholes are located distal to the 2-cm long balloon segment and 10 side holes are situated proximal to the balloon. Stack et al. ${ }^{12}$ compared the effect of inflating a standard balloon catheter with the autoperfusion catheter in the LCX of six dogs. During inflation of the standard catheter for $3 \pm 1$ minutes, five developed ST-segment elevation, five had ventricular tachycardia or fibrillation (one fatal), and six had left ventricular dysfunction detected by contrast ventriculography. The autoperfusion catheter was inflated for 37 \pm 10 minutes in the remaining five dogs. None of the dogs had evidence of ST-segment elevation, ventricular arrhythmias, or abnormal wall motion.

Preliminary reports of clinical studies using the autoperfusion catheter are encouraging. ${ }^{12}$ Stack et al. ${ }^{12}$ employed the autoperfusion catheter in four patients who had either total or subtotal coronary occlusion with chest pain and ST-segment devia-

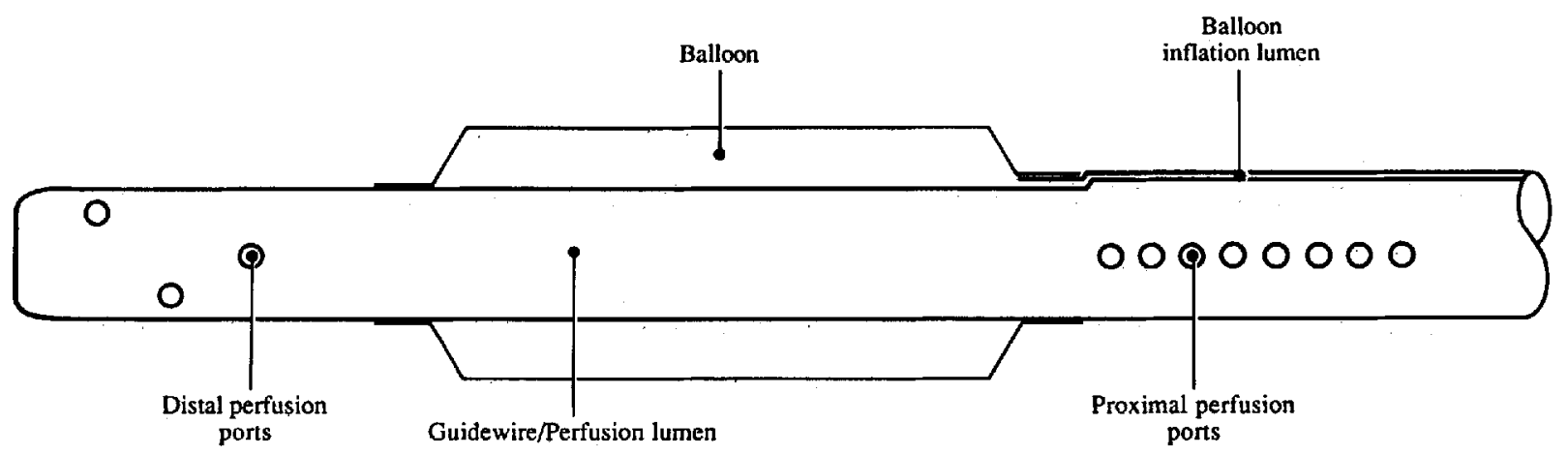

Figure 5. Schematic diagram of the distal segment of an autoperfusion catheter (adapted from Figure 1, reference 11). 


\section{PTCA HARDWARE}

tion after unsuccessful PTCA. After inflations ranging from 14 to 31 minutes, three of four patients had persistent reduction of the stenosis, and did not require bypass surgery. The ability of the autoperfusion system to mitigate myocardial ischemia during balloon inflation may prove useful in patients with multivessel disease or left ventricular dysfunction, and in patients with abrupt closure.

\section{Summary}

Successful performance of PTCA depends on the operator's ability to select appropriate equipment for a particular case. An $8 \mathrm{~F}$, soft tip guiding catheter, an over-the-wire balloon catheter, and a $0.014^{\prime \prime}$ floppy or flexible guidewire should allow successful completion of most straightforward cases with a low risk of intimal injury. Dilatation of distal and/or tight lesions, especially in tortuous arteries, may require the use of equipment that poses a somewhat higher risk of intimal dissection but provides greater support: Amplatz or $9 \mathrm{~F}$ guiding catheters, and guidewires that are more steerable and easily shaped, such as $0.016^{\prime \prime}$ or $0.018^{\prime \prime}$ standard wires.

Over-the-wire systems or the monorail system permit rapid placement of larger size balloon catheters or a bail-out catheter, and thus provide the greatest margin of safety during dilatation of stenoses that are proximal or pose a high risk of abrupt closure. Also, over-the-wire systems may be advantageous in patients with poor left ventricular function or multivessel disease, who may not tolerate prolonged ischemia due to abrupt closure. The smaller shaft "micro" catheters, such as the Hartzler models and the Probe, ${ }^{\mathrm{TM}}$ may facilitate the dilatation of stenoses located in small branches or distal segments which would not be bypassed if abrupt closure develops.

Innovative equipment, such as a combined laser and angioscopic catheter ${ }^{13}$ and a balloon catheter with a Doppler probe mounted on the tip,${ }^{14}$ may provide the capability of monitoring the success of coronary angioplasty by direct visualization or the measurement of coronary blood flow velocity. Hopefully, technological advances in other devices, such as atherectomy and laser catheters, and coronary stents, will permit the dilatation of steno- ses with even less risk and greater success in the future.

\section{References}

1. Detre K, Holubkov R, Kelsey S, Cowley M, Kent K, Williams D, Myler R, Faxon D, Holmes D, Jr, Bourassa M, Block P, Gosselin A, Bentivoglio L, Leatherman L, Dorros G, King III S, Galichia J, Al-Bassam M, Leon M, Robertson T, Passamani E. Percutaneous transluminal coronary angioplasty in 1985-1986 and 1977-1981. N Engl J Med 1988; 318:265-270.

2. Van Tassel RA, Gobel FL, Rydell MA, Vlodaver Z, MacCarter DJ. A less traumatic catheter for coronary arteriography. Cathet Cardiovas Diagn 1985; 11:187-199.

3. Roubin GS, DouglasJS, King SB III, Lin S, Hutchinson N, Thomas RG, Gruentzig AR. Influence of balloon size on mitral success, acute complications, and restenosis after percutaneous transluminal coronary angioplasty. A prospective randomized study. Circulation 1988; 78:557565.

4. Redd DCB, Roubin GS, Leimgruber PP, Abi-Mansour P, Douglas Jr JS, King SB Jr III. The transstenotic pressure gradient trend as a predictor of acute complications after percutaneous transluminal coronary angioplasty. Circulation 1987; 76:792-801.

5. Leimgruber PP, Roubin MB, Hollman J, Cotsonis GA, Meier B, Douglas JS, King SB, III, Gruentzig AR. Restenosis after successful coronary angioplasty in patients with single-vessel disease. Circulation 1986;73:710-717.

6. Thomas ES, Williams DO, Neiderman AL, Douglas JS, King SB III. Efficacy of a new angioplasty catheter for severely narrowed coronary lesions. J Am Coll Cardiol $1988 ; 12: 694-702$.

7. Dorros G, Lewin RL, Mathiak L. Probe, a balloon wire: initial experience. Cathet Cardiovasc Diagn 1988; 14:286-288.

8. Finci L, Meier B, Roy P, Steffenino G, Rutishauser W. Clinical experience with the monorail balloon catheter for coronary angioplasty. Cathet Cardiovasc Diagn 1988; $14: 206-212$

9. Hinohara T, Simpson JB, Phillips HR, Behar VS, Peter RH, Kong Y, Carlson EB, Stack RS. Transluminal catheter reperfusion: a new technique to reestablish blood flow after coronary occlusion during percutaneous transluminal coronary angioplasty. Am J Cardiol 1986; 57:684686.

10. Werter C, El Gamal M, Bonnier H, Michels R, Van Gelder L, Krieken AVD. Coronary reperfusion with a new catheter in six patients with acute occlusion after angioplasty. Cathet Cardiovasc Diagn 1988; 14:238-242.

11. Turi ZG, Campbell CA, Gottimukkala MV, Kloner RA. Preservation of distal coronary perfusion during prolonged balloon inflation with an autoperfusion angioplasty catheter. Circulation 1987; 75:1273-1280.

12. Stack RS, Quigley PJ, Collins G, Phillips HR. Perfusion balloon catheter. Am J Cardiol 1988; 61:77G-80G.

13. Abela GS, Seeger JM, Barbieri E, Franzini D, Fenech A, Pepine CJ, Conti CR. Laser Angioplasty with angioscopic guidance in humans. J Am Coll Cardiol 1986; 8:184-192.

14. Serruys PW, Juilliere Y, Zijlstra F, Beatt KJ, De Feyter PJ, Suryapranata H, Brand MVD, Roelandt J. Coronary blood flow velocity during percutaneous transluminal coronary angioplasty as a guide for assessment of the functional result. Am J Cardiol 1988; 61:253-259. 